\title{
CD Spectroscopy of Peptides and Proteins Bound to Large Unilamellar Vesicles
}

\author{
Alexey S. Ladokhin • Mónica Fernández-Vidal • \\ Stephen H. White
}

Received: 29 June 2010/ Accepted: 19 July 2010/Published online: 13 August 2010

(C) The Author(s) 2010. This article is published with open access at Springerlink.com

\begin{abstract}
Circular dichroism (CD) spectroscopy is an essential tool for determining the conformation of proteins and peptides in membranes. It can be particularly useful for measuring the free energy of partitioning of peptides into lipid vesicles. The belief is broadly held that such $\mathrm{CD}$ measurements can only be made using sonicated small unilamellar vesicles (SUVs) because light scattering associated with extruded large unilamellar vesicles (LUVs) is unacceptably high. We have examined this issue using several experimental approaches in which a chiral object (i.e., peptide or protein) is placed both on the membrane and outside the membrane. We show that accurate CD spectra can be collected in the presence of LUVs. This is important because SUVs, unlike LUVs, are metastable and consequently unsuitable for equilibrium thermodynamic measurements. Our data reveal that undistorted CD spectra of peptides can be measured at wavelengths above $200 \mathrm{~nm}$ in the presence of up to $3 \mathrm{mM}$ LUVs and above $215 \mathrm{~nm}$ in the presence of up to $7 \mathrm{mM}$ LUVs. We introduce a simple way of characterizing the effect on $\mathrm{CD}$ spectra of light
\end{abstract}

\footnotetext{
A. S. Ladokhin $(\bowtie)$

Department of Biochemistry and Molecular Biology, University of Kansas Medical Center, Kansas City, KS 66160-7421, USA e-mail: aladokhin@kumc.edu
}

\section{Fernández-Vidal · S. H. White}

Department of Physiology and Biophysics and Program in Macromolecular Structure, University of California, Irvine, CA 92697-4560, USA

e-mail: stephen.white@uci.edu

Present Address:

M. Fernández-Vidal

Department of Peptide and Protein Chemistry,

IIQAB-CSIC, 08034 Barcelona, Spain scattering and absorption arising from suspensions of vesicles of any diameter. Using melittin as an example, we show that CD spectroscopy can be used to determine the fractional helical content of peptides in LUVs and to measure their free energy of partitioning of into LUVs.

Keywords Large unilamellar vesicle $\cdot$ Small unilamellar vesicle $\cdot$ Peptide conformation $\cdot$ Secondary structure . Membrane binding

\section{Introduction}

Circular dichroism (CD) spectroscopy is the most widely used method in structural biology for determining the secondary structure of peptides and proteins. It has proven to be invaluable for studies of the binding and folding of membrane active peptides. With only a few exceptions (Wimley et al. 1998; Ladokhin and White 1999, 2001, 2004; Ladokhin et al. 1999), small unilamellar vesicles (mean diameter $\sim 30 \mathrm{~nm}$, SUVs) made by sonication (Huang 1969) are used nearly exclusively for such studies in order to minimize the effects of light scattering on the observed CD spectra. The difficulty with SUVs is that they are metastable (Schmidt et al. 1981; Wong et al. 1982) and produce anomalous peptide partitioning as a result of high vesicle curvature (Greenhut et al. 1986; Seelig and Ganz 1991; Plager and Nelsestuen 1994; Ladokhin et al. 2000). This is confirmed by high-sensitivity isothermal titration calorimetry, which reveals that binding enthalpies observed with SUVs are generally more exothermic than those observed with extruded large unilamellar vesicles (mean diameter $\sim 100 \mathrm{~nm}$, LUVs) (Seelig and Ganz 1991; Beschiaschvili and Seelig 1992; Gazzara et al. 1997; Wieprecht et al. 2000). SUVs are therefore not generally 
suitable for thermodynamic measurements. In contrast, LUVs produced by extrusion (Enoch and Strittmatter 1979) are suitable for thermodynamic measurements because they are equilibrium structures. An important methodological question thus concerns the conditions under which accurate $C D$ measurements can be carried out in the presence of LUVs.

We described earlier the procedures for making artifactfree fluorescence measurements (Ladokhin et al. 2000) using LUVs or SUVs. Here, we introduce a simple method for determining the conditions under which accurate CD spectra can be obtained for a given vesicle preparation, regardless of diameter. We demonstrate for LUVs that useful CD spectra of peptides can be obtained in the range of $215-260 \mathrm{~nm}$ in the presence of up to $7 \mathrm{mM}$ LUVs. Using melittin as an example, we show that it is possible by means of CD spectroscopy to determine accurately the free energy of peptide partitioning $(\Delta G)$ into LUVs as well as the helical fraction of the LUV-bound peptide.

\section{Materials and Methods}

\section{Materials}

1-Palmitoyl-2-oleoyl-sn-glycerol-3-phosphatidylcholine (POPC) was obtained from Avanti Polar Lipids (Alabaster, $\mathrm{AL}$ ) and melittin (sequencing grade) from Sigma (St. Louis, MO). The peptide Ac-Y(AEAAKA $)_{4} \mathrm{~F}-\mathrm{NH}_{2}$ was a gift from Drs. Martin Scholtz (Texas A \& M) and Robert Baldwin (Stanford). The buffer, a $10 \mathrm{mM}$ potassium phosphate solution ( $\mathrm{pH}$ 7.0), was used to reduce the UV absorbance in $\mathrm{CD}$ experiments.

\section{Preparation of Vesicles}

A defined amount of lipid in chloroform was dried first under nitrogen and then overnight under high vacuum. Typically, 1-2 $\mathrm{ml}$ of buffer (10 $\mathrm{mM}$ potassium phosphate solution, $\mathrm{pH}$ 7.0) was added to the lipid and the dispersion was extensively vortexed. For preparation of SUVs, the lipid dispersion was sonicated under nitrogen gas using a titanium tip ultrasonicator until the solution became transparent (Huang 1969). An ice-water bath was used to reduce further the possibility of lipid oxidation during sonication. Metal debris from the titanium tip was removed by centrifugation (Eppendorf table-top centrifuge, $25 \mathrm{~min}$ at 10,000 rev/min). LUVs of the lipids with an approximate diameter of $0.1 \mu \mathrm{M}$ were formed by extrusion under nitrogen through Nucleopore polycarbonate membranes (10 times through two stacked $0.1-\mu \mathrm{m}$ filters), using the method of Mayer et al. (1986).

\section{Circular Dichroism}

CD measurements were performed using a Jasco-720 spectropolarimeter (Japan Spectroscopic Company, Tokyo, Japan). Normally, 10-30 scans were recorded at ambient temperature $\left(\sim 25^{\circ} \mathrm{C}\right)$ between 190 and $260 \mathrm{~nm}$, using a 1-mm optical path. Spectra were corrected for background scattering by subtracting a vesicle-only spectrum measured with an appropriate concentration of vesicles in buffer, without the peptide. Measured values of ellipticity $(\Theta)$ were converted into the ellipticity per amino acid residue $[\Theta]$. CD and absorbance were measured in the same cuvette in order to minimize errors in determination of molar ellipticity.

\section{Calculated CD Spectra}

Calculated CD spectra for melittin bound $100 \%$ to LUVs and SUVs were obtained from the spectra for 0 and $5 \mathrm{mM}$ lipid concentrations. The fraction of melittin bound at $5 \mathrm{mM}$ was estimated to be $70 \%$ for LUVs and $95 \%$ for SUVs, based upon the measured partitioning free energy, $\Delta G$. The contribution of the free peptide was subtracted (30\% for LUVs, $5 \%$ for SUVs) from the spectra measured in the presence of $5 \mathrm{mM}$ lipid in order to estimate the spectra for $100 \%$ binding. Nonlinear least-squares analysis was performed using the Origin 7.0 software package (OriginLab, Northampton, MA).

\section{Absorbance Spectroscopy}

UV absorbance was measured with a Cary 3E spectrophotometer (Varian Analytical Instruments, Sugar Land, TX). Molar concentrations of the peptides were determined using a molar extinction coefficient of $\varepsilon_{274 \mathrm{~nm}}=$ $1,440 \mathrm{M}^{-1} \mathrm{~cm}^{-1}$ for tyrosine and $\varepsilon_{280 \mathrm{~nm}}=5,600 \mathrm{M}^{-1} \mathrm{~cm}^{-1}$ for tryptophan. For measurements of apparent absorbance of vesicle preparations caused by light scattering and by buffer absorbance, the Jasco-720 was used in order to assure self-consistent correction of CD spectra.

\section{Results and Discussion}

Most studies of peptide-bilayer interactions by CD spectroscopy involve experiments in which peptides or proteins are present in both bound and unbound forms. There are two potential artifacts in such measurements. For the unbound peptide, the scattering of light by vesicles can distort the UV absorbance of the chiral peptide. This is also true for peptides bound to the vesicles, but an additional distortion of the CD signal from the bound peptide might 
exist because the bound peptide plus vesicle represent together a chiral scattering object. It is thus important to be sure that the $\mathrm{CD}$ spectrum of the bound peptide is not distorted by being part of a chiral scattering object.

Experiments with Peptides Outside the Membrane

SUVs are widely used because of their reduced light scatter in spectroscopic measurements. Figure 1 shows the dramatic increases in light scattering that accompany increasing concentrations of LUVs and SUVs from 0.25 to $7.0 \mathrm{mM}$ as a function of wavelength. The optical density, which was recorded using the Jasco-720 spectropolarimeter, varies as $1 / \lambda^{4}$ down to $210 \mathrm{~nm}$ because of light scattering and then increases much more rapidly due to absorbance by the buffer. LUVs scattered more strongly than SUVs, as expected; but the scattering from SUVs was nevertheless significant.

The spectra of membrane-active peptides change as they are adsorbed into vesicles because binding generally induces secondary structure formation (Wimley et al. 1998; Ladokhin and White 1999). This complicates the determination of the effect of light scattering on the CD spectra of peptides in the presence of vesicles. A simple way to determine the effect of scattered light on spectra is to place the peptide and vesicles in separate cuvettes, as shown schematically in Fig. 2. For the data presented in Fig. 3, a fixed concentration of the peptide melittin was placed in a cuvette containing methanol (cell 1), which induced maximal secondary structure and yielded CD spectra similar to those of peptide bound to vesicles. Vesicle suspensions of increasing lipid concentration were placed in the other cuvette (cell 2). Although cell 2 is closer to the detector in

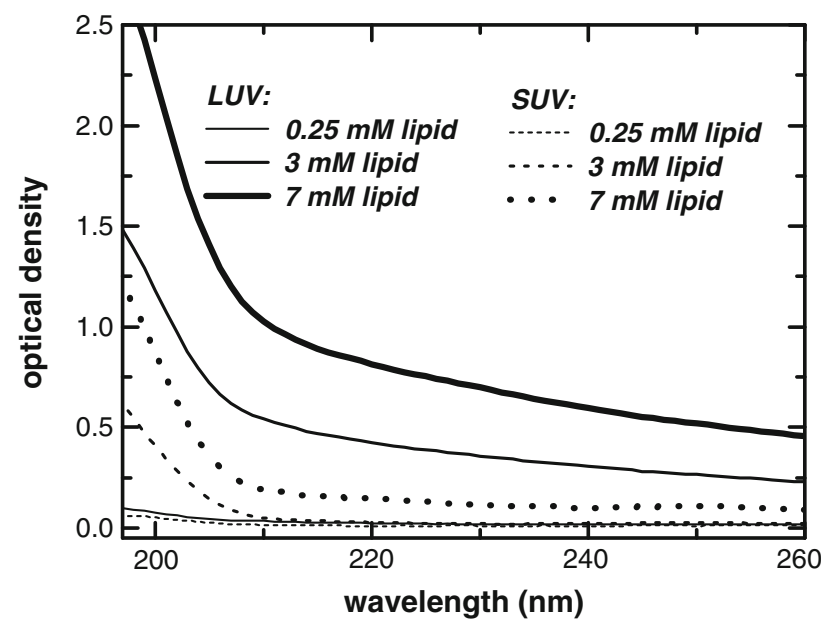

Fig. 1 Optical densities as a function of wavelength for suspensions of LUVs (solid lines) and SUVs (dashed lines). Optical densities of POPC vesicles at lipid concentrations of $0.25,3$ and $7 \mathrm{mM}$ were determined using a Jasco-720 spectropolarimeter (see text)

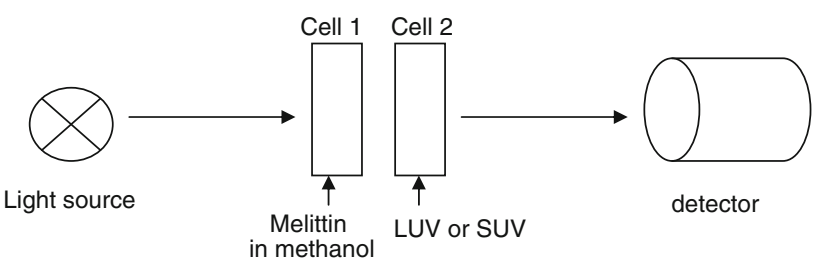

Fig. 2 Schematic representation of the two-cuvette experimental scheme for studying the influence on CD spectra of peptides of light scattering caused by LUVs. Drawing is not to scale. A standard solution of melittin in methanol was placed in cell 1 , while LUV suspensions of different concentrations were placed in cell 2. The results presented here did not depend on whether cell 1 or cell 2 was closer to the light source
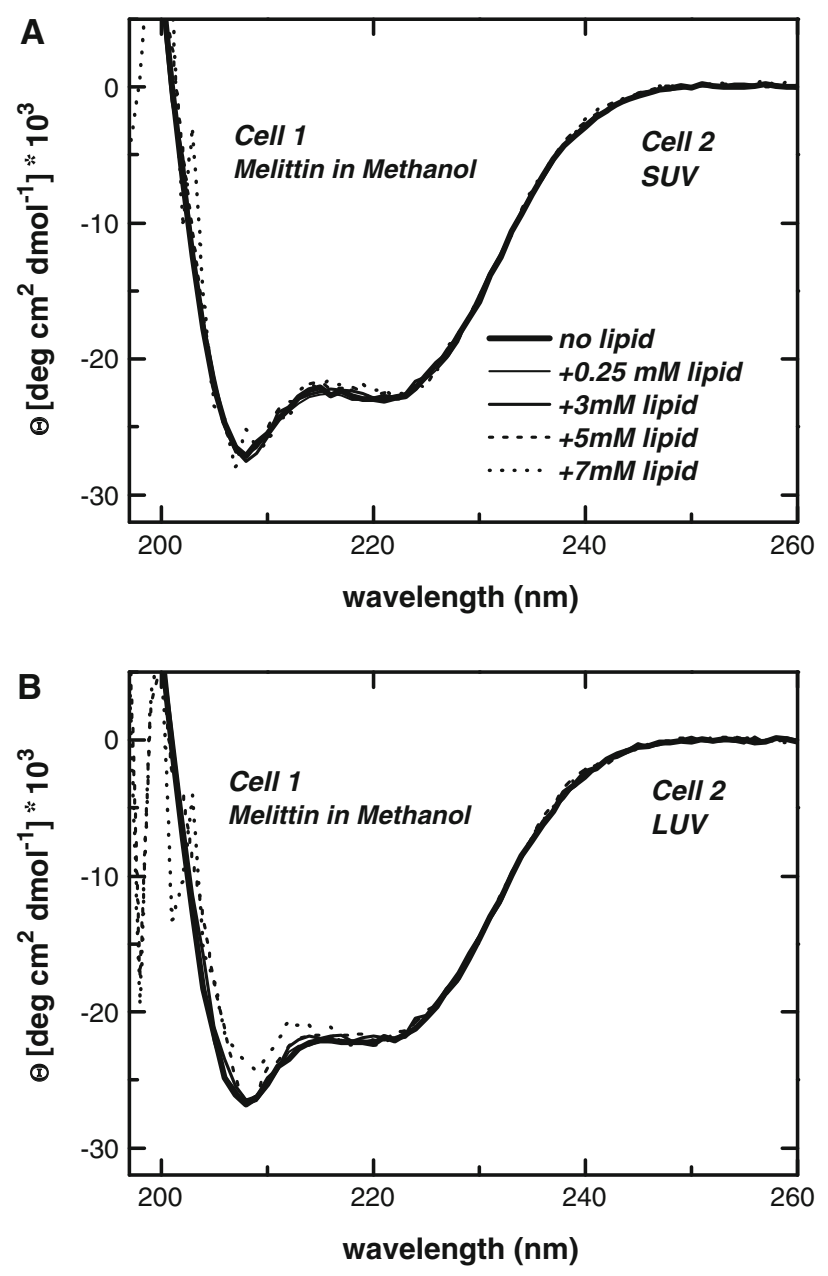

Fig. $3 \mathrm{CD}$ spectra of melittin in methanol $(40 \mu \mathrm{M}$, cell 1$)$ recorded in the two-cuvette experiment shown in Fig. 2. a Cell 2 containing SUV suspensions at concentrations up to $7 \mathrm{mM}$. Undistorted CD spectra of melittin with up to $7 \mathrm{mM}$ SUVs can be obtained for the spectral region above $200 \mathrm{~nm}$. b Cell 2 containing LUV suspensions at concentrations up to $7 \mathrm{mM}$. Undistorted CD spectra of melittin can be obtained with up to $5 \mathrm{mM}$ LUVs for the spectral region above $200 \mathrm{~nm}$ and with up to $7 \mathrm{mM}$ for the spectral region above $215 \mathrm{~nm}$ (see values of molar ellipticity in Table 1) 
Fig. 2, the results were the same when the cell positions were switched.

Figure 3 shows the CD spectrum of melittin in methanol, recorded from cell 1 while increasing the concentration of SUVs or LUVs in cell 2 (panels a and b, respectively). For a concentration of $7 \mathrm{mM}$ SUVs, the CD spectra were affected only slightly by light scattering. With LUVs in cell 2, the CD spectra of melittin in methanol were very similar to those with SUVs with up to $5 \mathrm{mM}$ lipid; the spectra coincided almost completely with those measured in the absence of lipid (see molar ellipticity values at $220 \mathrm{~nm}$ in Table 1). At $7 \mathrm{mM}$ LUVs, only a slight decrease of the signal could be observed at wavelengths below $215 \mathrm{~nm}$. The optical densities of samples in this wavelength region are quite high, meaning that this region should be discarded in accordance with general recommendations for CD samples (optical density should not exceed 1 unit). However, by reducing the optical path, the entire spectral region can be used, which is necessary for deconvolution of a $\mathrm{CD}$ spectrum into components associated with various elements of secondary structure (data not shown); but if one is interested in detecting only changes in helical content at $222 \mathrm{~nm}$, the spectral region above $215 \mathrm{~nm}$ is sufficient.

How can one be certain that this two-cuvette approach provides a valid means for assessing the effect of light scattering on the CD spectra? This question can be answered only by recording spectra from peptides that are in the same cuvette as the vesicles. However, this cannot be done using a membrane-active peptide, such as melittin, because of the induction of secondary structure caused by binding to vesicles. We circumvented this problem by using the synthetic peptide Ac-Y(AEAAKA) ${ }_{4} \mathrm{~F}-\mathrm{NH}_{2}$ (Scholtz et al. 1991), which is strongly $\alpha$-helical in buffer but does not bind to vesicle membranes. The peptide was found by Scholtz et al. (1991) to be monomolecular and $\sim 60 \% \alpha$-helical in buffer. The blocking groups on the termini eliminate unfavorable charge-helix dipole interactions, and the saltbridged side-chain interactions are optimized by the $i, i+3$ spacing of the Glu and Lys residues. Using the experimentbased whole-residue interfacial hydrophobicity scale of Wimley and White (1996), the free energy of partitioning in POPC is estimated to be $+4 \mathrm{kcal} \mathrm{mol}^{-1}$, meaning that the peptide cannot partition significantly into neutral POPC vesicles.

Figure 4a shows the CD spectra of Ac-Y(AEAAKA) ${ }_{4} \mathrm{~F}-$ $\mathrm{NH}_{2}$ in buffer containing LUVs at concentrations of up to $7 \mathrm{mM}$. The value of the molar ellipticity of the peptide at

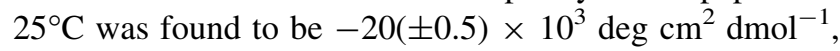
which is in agreement with the value measured by Scholtz et al. (1991). The spectra have features that are characteristic of an $\alpha$-helical structure: minima at 222 and $208 \mathrm{~nm}$ and a maximum at around $190 \mathrm{~nm}$. The CD spectra of the peptide shown in Fig. 4a are practically indistinguishable (see molar ellipticity values in Table 1). Figure 4b shows the CD spectra obtained with peptide in buffer in cell 1 and increasing concentrations of LUVs in cell 2. The spectra obtained in this two-cuvette experiment are almost identical to the spectra obtained in Fig. 4a. This validates the two-cuvette experiment and confirms the assumption that Ac-Y(AEAAKA) ${ }_{4} \mathrm{~F}-\mathrm{NH}_{2}$ does not bind to POPC vesicles.

\section{Experiments with Peptides and Proteins Bound} to the Membrane

In the previous section we demonstrated that unpolarized scattering from LUVs does not affect CD measurements of the peptides that reside outside the scattering object. In order to demonstrate that we can accurately measure CD of membrane-bound proteins and peptides, we need to demonstrate the lack of distortion due to differential scattering between the left- and right-polarized light by placing the

Table 1 Changes of molar ellipticity of Ac-Y(AEAAKA) ${ }_{4} \mathrm{~F}-\mathrm{NH}_{2}$ and melittin under different conditions

\begin{tabular}{|c|c|c|c|c|}
\hline $\begin{array}{l}\text { POPC vesicle } \\
\text { concentration }\end{array}$ & $\begin{array}{l}\mathrm{Y}(\mathrm{AEAAKA})_{4} \mathrm{~F} \\
(\text { same cell })^{\mathrm{a}} \\
\Theta_{222}{ }^{\mathrm{b}}\end{array}$ & 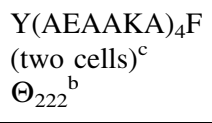 & $\begin{array}{l}\text { Melittin (methanol) } \\
\text { SUV }^{\mathrm{d}} \\
\Theta_{222}{ }^{\mathrm{b}}\end{array}$ & $\begin{array}{l}\text { Melittin (methanol) } \\
\text { LUV }^{\mathrm{d}} \\
\Theta_{222} \mathrm{~b}\end{array}$ \\
\hline No lipid & $-20,100$ & $-20,300$ & $-22,900$ & $-22,100$ \\
\hline$+0.25 \mathrm{mM}$ & $-20,100$ & $-20,400$ & $-23,200$ & $-22,000$ \\
\hline$+3 \mathrm{mM}$ & $-19,800$ & $-20,100$ & $-22,900$ & $-21,900$ \\
\hline$+5 \mathrm{mM}$ & $-19,700$ & $-20,100$ & $-22,700$ & $-21,600$ \\
\hline$+7 \mathrm{mM}$ & $-19,700$ & $-19,900$ & $-22,600$ & $-21,500$ \\
\hline
\end{tabular}

\footnotetext{
a The peptide (which does not bind to vesicles) and the LUVs are in the same cuvette

${ }^{b}$ Units: $\operatorname{deg} \mathrm{cm}^{2} \mathrm{dmol}^{-1}$. Errors of determination of $\Theta$ in the presence of lipids are estimated to be $10 \%$

c The peptide (in buffer) and the LUVs are in different cuvettes

d The melittin in methanol and the vesicles in buffer are in separate cuvettes
} 

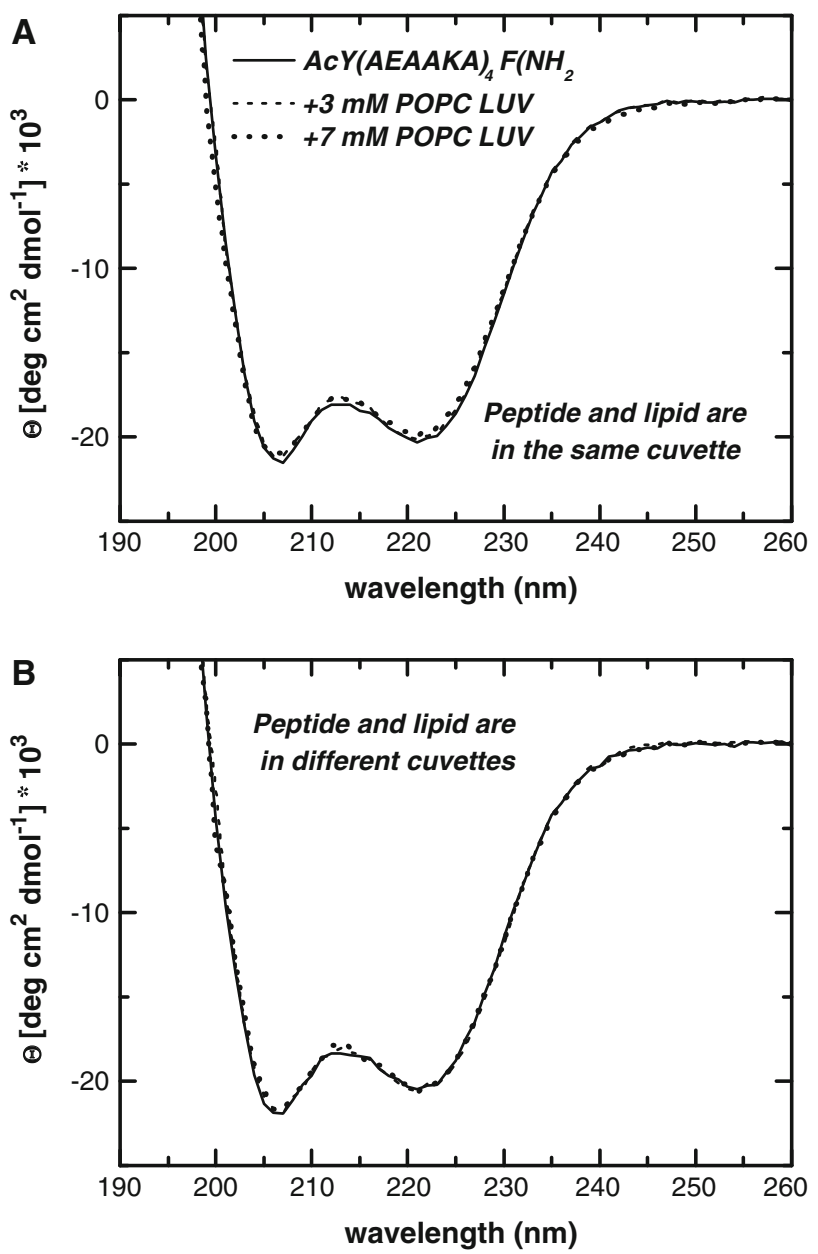

Fig. $4 \mathrm{CD}$ spectra of the nonbinding peptide Ac-Y(AEAAKA) ${ }_{4} \mathrm{~F}-$ $\mathrm{NH}_{2}(40 \mu \mathrm{M})$ in the presence of vesicles. a CD spectra obtained with the peptide in the same cuvette as the lipid. b CD spectra of an aqueous solution of $\mathrm{Ac}-\mathrm{Y}(\mathrm{AEAAKA})_{4} \mathrm{~F}-\mathrm{NH}_{2}$ in cell 1 measured in the presence of increasing concentrations of LUVs in cell 2 (see values of molar ellipticity in Table 1). The spectra are virtually identical to the spectra of (a). This validates the use of the two-cuvette experiment for studying the influence of light scattering on $\mathrm{CD}$ spectra obtained from solutions containing unilamellar vesicles of any size

chiral object (polypeptide chain) into the scattering object (vesicle). This is not an easy experiment to construct as most peptides undergo conformational change upon interaction with the lipid bilayer due to partitioning-folding coupling (Wimley et al. 1998; Ladokhin and White 1999; White et al. 1998). Thus, we used a large protein, Annexin B12, which has been shown to associate interfacially with the membranes in the presence of $\mathrm{Ca}^{2+}$ without rearrangements of the secondary structure (Isas et al. 2003). As expected, our measurements indicate that aqueous and LUV-associated Annexin B12 have essentially the same CD spectrum (Fig. 5), thus confirming the absence of specific artifacts originating from the placement of the chiral object on the scattering vesicle.

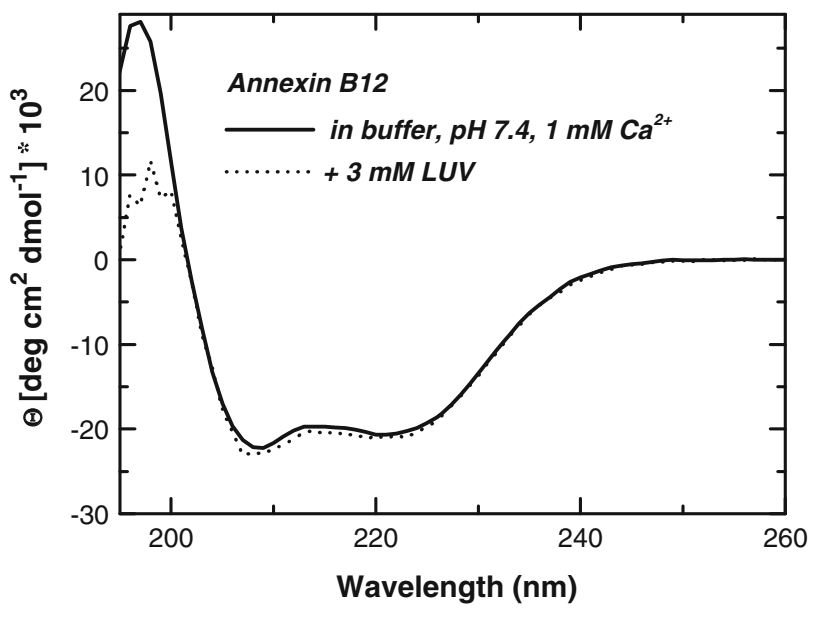

Fig. 5 CD measurements of Annexin B12 in solution (solid line) and when bound to LUVs (dotted line) via a $\mathrm{Ca}^{2+}$-dependent interfacial mechanism. Because no conformational rearrangement is expected, the coinciding spectra confirm the absence of specific artifacts due to differential scattering by LUVs when a chiral object is placed on the scattering object

To further demonstrate the use of LUVs for determining structural and thermodynamic properties of peptide binding in a real experiment, we used melittin, which changes its conformation upon partitioning into lipid bilayers (Ladokhin and White 1999; Vogel 1981; Kuchinka and Seelig 1989; Beschiaschvili and Baeuerle 1991). Melittin in solution has a random coil structure, whereas upon partitioning into lipid membranes it adopts a characteristic $\alpha$-helix ellipticity at $222 \mathrm{~nm}$ that shows a progressive increase with increasing lipid concentration for both LUVs and SUVs (Fig. 6). These results show that changes in the CD spectra that depend on lipid concentration can be used to determine quantitatively the binding isotherm and, consequently, the free energy of partitioning. Using the formula $\Delta G=-\mathrm{RT} \ln K_{x}$, where $K_{x}$ is the partition coefficient (White et al. 1998), the data of Fig. 6 yield $\Delta G=-6.0 \pm 0.4 \mathrm{kcal} \mathrm{mol}^{-1}$ for melittin partitioning into POPC LUVs and $\Delta G=-7.2 \pm 0.3 \mathrm{kcal} \mathrm{mol}^{-1}$ for SUVs. Previously, we reported a similar difference between SUV and LUV titration of melittin using intrinsic fluorescence (Ladokhin et al. 2000). The difference is not surprising because SUVs are nonequilibrium systems known to produce artificially high binding affinity (as discussed in Ladokhin et al. 2000).

An important question is whether the spectra of melittin bound to SUVs and LUVs are inherently the same. Comparisons are complicated for several reasons: (1) the light scattering of LUVs at high lipid concentrations, (2) possible structural differences between SUVs and LUVs that might affect the structure of bound melittin and (3) differences in binding affinity (which we know from Fig. 6). An approach to this problem is to reconstruct spectra for 


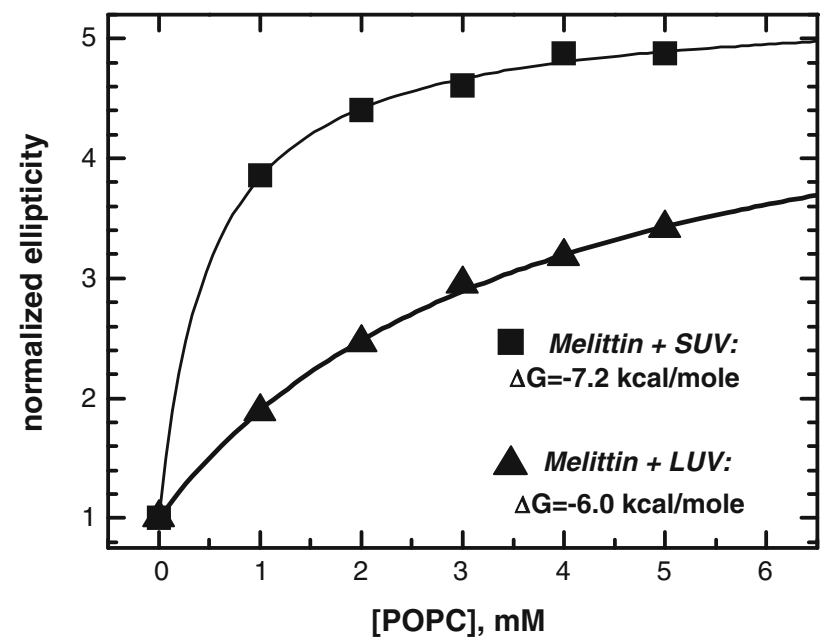

Fig. 6 CD measurements of melittin titration by SUVs (squares) and LUVs (triangles). Due to packing distortions, SUVs have higher apparent affinity for many peptides, including melittin (see Ladokhin et al. 2000 and text for more)

$100 \%$ binding to LUVs and SUVs, using spectra obtained for $<100 \%$ binding, as described in "Materials and Methods". Figure 7 shows the calculated CD spectra of melittin for $100 \%$ binding to SUVs and LUVs. The value of the molar ellipticity at $222 \mathrm{~nm}\left[\Theta_{222}\right]$ is estimated to be $-23.7 \times 10^{3} \mathrm{deg} \mathrm{cm} \mathrm{dmol}^{-1}$, which is the same for both spectra and corresponds to values reported earlier (Vogel 1981). The spectra coincide down to $217 \mathrm{~nm}$, with only slight differences at shorter wavelengths, which could be due to the different $\mathrm{CD}$ signatures of the two systems.

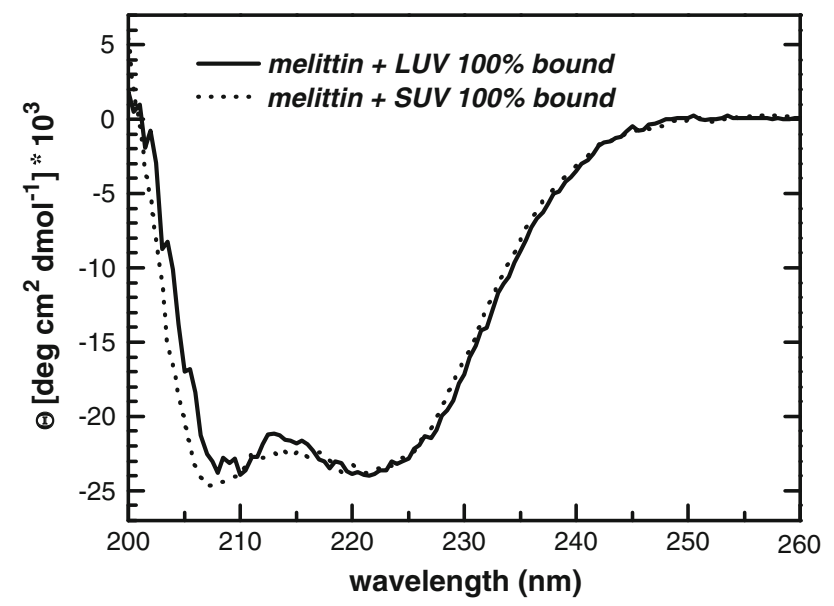

Fig. 7 Calculated CD spectra for melittin completely bound to POPC LUVs and SUVs. The spectra were reconstructed from the measurements in the presence of $5 \mathrm{mM}$ lipid, as described in "Materials and Methods". The two spectra gave identical molar ellipticity values of $[\Theta]=-23,700 \mathrm{deg} \mathrm{cm}^{2} \mathrm{dmol}^{-1}$, corresponding to approximately $70 \%$ peptide helicity
However, the overall agreement of the two spectra is good enough to assume that the structures of melittin are very similar in the two systems.

The mean residue ellipticity of $-23.7 \times 10^{3} \mathrm{deg} \mathrm{cm}$ $\mathrm{dmol}^{-1}$ at $222 \mathrm{~nm}$ agrees with results obtained in earlier studies with SUVs and membrane-mimicking solvents (Ladokhin and White 1999; Vogel 1981; Kuchinka and Seelig 1989; Beschiaschvili and Baeuerle 1991). The fractional helical content $\left(\mathrm{f}_{\alpha}\right)$ of melittin can be estimated using the formula $\mathrm{f}_{\alpha}=\left(\Theta-\Theta_{\mathrm{RC}}\right) /\left(\Theta_{\mathrm{H}}-\Theta_{\mathrm{RC}}\right)$, where $\Theta$ is the observed ellipticity and $\Theta_{\mathrm{RC}}$ and $\Theta_{\mathrm{H}}$ are the limiting values for a completely random coil and a completely helical conformation, respectively. Although this formula is simple and well accepted, there is a certain ambiguity in the result, due to the uncertainty in prediction of what the actual values for $\Theta_{\mathrm{RC}}$ and $\Theta_{\mathrm{H}}$ should be (Greenfield and Fasman 1969; Luo and Baldwin 1997; Rohl and Baldwin 1997; Shalongo and Stellwagen 1997). Here, we used the following values $(222 \mathrm{~nm}): \Theta_{\mathrm{RC}}=-1.5 \times 10^{3} \mathrm{deg} \mathrm{\textrm {cm } ^ { 2 }}$

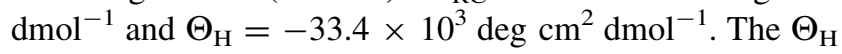
number is calculated at $25^{\circ} \mathrm{C}$ for a peptide the size of melittin according to Luo and Baldwin (1997). The CD spectra of melittin bound to POPC LUVs $\left(25^{\circ} \mathrm{C}\right)$ reveal a conformation with $\sim 70 \% \alpha$-helical content, corresponding to $18-19$ amino acids, which is in good agreement with results obtained in various membrane and membranemimicking systems by different methods (Vogel 1981; Lam et al. 2001; Brown et al. 1982).

Our results demonstrate the ease with which LUVs can be used in studies of peptide-bilayer interactions. As for fluorescence studies of peptide partitioning into lipid bilayers (Ladokhin et al. 2000), there is no apparent need to use SUVs in preference to LUVs for optical reasons. Indeed, because they are free of curvature-stress and are equilibrium structures (a necessary condition for thermodynamic measurements), LUVs should be used in preference to SUVs. LUVs are perfectly suitable for both fluorescence and $\mathrm{CD}$ measurements that require lipid bilayers. We can thus think of no compelling reason for using SUVs in studies of peptide-bilayer interactions.

Acknowledgments We thank Drs. Martin Scholtz (Texas A \& M) and Robert Baldwin (Stanford) for the gift of the Ac-Y(AEAAKA) ${ }_{4} \mathrm{~F}$ $\mathrm{NH}_{2}$ peptide and Dr. Harry Haigler (UC-Irvine) for the gift of Annexin B12. This research was supported by grants GM46823 and GM74637 (S. H. W) and GM69783 (A. S. L.) from the National Institute of General Medical Sciences. Additional support was provided by GM86685 (S. H. W.) from the National Institute of General Medical Sciences and the National Institute of Neurological Disorders and Stroke.

Open Access This article is distributed under the terms of the Creative Commons Attribution Noncommercial License which permits any noncommercial use, distribution, and reproduction in any medium, provided the original author(s) and source are credited. 


\section{References}

Beschiaschvili G, Baeuerle H-D (1991) Effective charge of melittin upon interaction with POPC vesicles. Biochim Biophys Acta 1068:195-200

Beschiaschvili G, Seelig J (1992) Peptide binding to lipid bilayers: nonclassical hydrophobic effect and membrane-induced pk shifts. Biochemistry 31:10044-10053

Brown LR, Braun W, Kumar A, Wüthrich K (1982) High resolution nuclear magnetic resonance studies of the conformation and orientation of melittin bound to a lipid-water interface. Biophys J 37:319-328

Enoch HG, Strittmatter P (1979) Formation and properties of 1000- $\AA$ diameter, single-bilayer phospholipid vesicles. Proc Natl Acad Sci USA 76:145-149

Gazzara JA, Phillips MC, Lund-Katz S, Palgunachari MN, Segrest JP, Anantharamaiah GM, Rodrigueza WV, Snow JW (1997) Effect of vesicle size on their interaction with class A amphipathic helical peptides. J Lipid Res 38:2147-2154

Greenfield N, Fasman GD (1969) Computed circular dichroism spectra for the evaluation of protein conformation. Biochemistry $8: 4108-4116$

Greenhut SF, Bourgeois VR, Roseman MA (1986) Distribution of cytochrome $\mathrm{b}_{5}$ between small and large unilamellar phospholipid vesicles. J Biol Chem 261:3670-3675

Huang C-H (1969) Studies on phosphatidylcholine vesicles. Formation and physical characteristics. Biochemistry 8:344-352

Isas JM, Patel DR, Jao C, Jayasinghe S, Cartailler J-P, Haigler HT, Langen R (2003) Global structural changes in annexin 12: the roles of phospholipid, $\mathrm{Ca}^{2+}$, and $\mathrm{pH}$. J Biol Chem 278: 30227-30234

Kuchinka E, Seelig J (1989) Interaction of melittin with phosphatidylcholine membranes. Binding isotherm and lipid head-group conformation. Biochemistry 28:4216-4221

Ladokhin AS, White SH (1999) Folding of amphipathic $\alpha$-helices on membranes: energetics of helix formation by melittin. J Mol Biol 285:1363-1369

Ladokhin AS, White SH (2001) Protein chemistry at membrane interfaces: non-additivity of electrostatic and hydrophobic interactions. J Mol Biol 309:543-552

Ladokhin AS, White SH (2004) Interfacial folding and membrane insertion of a designed helical peptide. Biochemistry 43:5782-5791

Ladokhin AS, Selsted ME, White SH (1999) CD spectra of indolicidin antimicrobial peptides suggest turns, not polyproline helix. Biochemistry 38:12313-12319

Ladokhin AS, Jayasinghe S, White SH (2000) How to measure and analyze tryptophan fluorescence in membranes properly, and why bother? Anal Biochem 285:235-245
Lam Y-H, Wassall SR, Morton CJ, Smith R, Separovic F (2001) Solid-state NMR structure determination of melittin in a lipid environment. Biophys J 81:2752-2761

Luo PZ, Baldwin RL (1997) Mechanism of helix induction by trifluoroethanol: a framework for extrapolating the helix-forming properties of peptides from trifluoroethanol/water mixtures back to water. Biochemistry 36:8413-8421

Mayer LD, Hope MJ, Cullis PR (1986) Vesicles of variable sizes produced by a rapid extrusion procedure. Biochim Biophys Acta 858:161-168

Plager DA, Nelsestuen GL (1994) Direct enthalpy measurements of factor $\mathrm{X}$ and prothrombin association with small and large unilamellar vesicles. Biochemistry 33:7005-7013

Rohl CA, Baldwin RL (1997) Comparison of NH exchange and circular dichroism as techniques for measuring the parameters of the helix-coil transition in peptides. Biochemistry 36:8435-8442

Schmidt CF, Lichtenberg D, Thompson TE (1981) Vesicle-vesicle interactions in sonicated dispersions of dipalmitoylphosphatidylcholine. Biochemistry 20:4792-4797

Scholtz JM, Hong Q, York EJ, Stewart JM, Baldwin RL (1991) Parameters of helix-coil transition theory for alanine-based peptides of varying chain lengths in water. Biopolymers 31: $1463-1470$

Seelig J, Ganz P (1991) Nonclassical hydrophobic effect in membrane binding equilibria. Biochemistry 30:9354-9359

Shalongo W, Stellwagen E (1997) Dichroic statistical model for prediction and analysis of peptide helicity. Proteins 28:467-480

Vogel H (1981) Incorporation of melittin into phosphatidylcholine bilayers: study of binding and conformational changes. FEBS Lett 134:37-42

White SH, Wimley WC, Ladokhin AS, Hristova K (1998) Protein folding in membranes: determining the energetics of peptidebilayer interactions. Methods Enzymol 295:62-87

Wieprecht T, Apostolov O, Seelig J (2000) Binding of the antibacterial peptide magainin 2 amide to small and large unilamellar vesicles. Biophys Chem 85:187-198

Wimley WC, White SH (1996) Experimentally determined hydrophobicity scale for proteins at membrane interfaces. Nat Struct Biol 3:842-848

Wimley WC, Hristova K, Ladokhin AS, Silvestro L, Axelsen PH, White SH (1998) Folding of $\beta$-sheet membrane proteins: a hydrophobic hexapeptide model. J Mol Biol 277:1091-1110

Wong M, Anthony FH, Tillack TW, Thompson TE (1982) Fusion of dipalmitoylphosphatidylcholine vesicles at $4^{\circ} \mathrm{C}$. Biochemistry 21:4126-4132 